\title{
Pengaruh Variasi Radius-Dalam Rim Terhadap Pengurangan Massa dan Momen Inersia Massa Dengan Studi Kasus Benda Putar Berdiameter $10 \mathrm{~cm}$
}

\author{
Eka Taufiq Firmansjah \\ Jurusan Teknik Mesin, Fakultas Teknik Industri, ITENAS, Bandung \\ Email: ekatf@itenas.ac.id
}

\begin{abstract}
ABSTRAK
Mesin terdiri dari sekumpulan elemen mesin yang diam dan bergerak. Elemen mesin yang bergerak dengan gerakan berputar disebut benda putar. Pada beberapa kasus seringkali diinginkan pengurangan massa dari benda putar tersebut untuk alasan ekonomis, biasanya untuk elemen mesin yag diproduksi massal. Namun pengurangan massa berakibat pada pengurangan momen inersia massa benda putar bersangkutan. Jika tuntutan perancangan tidak mempermasalahkan perubahan tersebut, maka pengurangan massa tidak menjadi masalah. Namun jika momen inersia massa tidak boleh terlalu rendah, maka harus dicari kompromi dimana pengurangan massa sebesar-besarnya namun penurunan momen inersia massa sekecil-kecilnya. Pada penelitian ini dilakukan studi kasus terhadap benda putar berjarijari $10 \mathrm{~cm}$ jari-jari dalam hub $2 \mathrm{~cm}$ dan jari-jari luar hub $4 \mathrm{~cm}$. Jumlah jari-jari ada 4 dengan lebar $1 \mathrm{~cm}$ dan tebal benda putar $0,5 \mathrm{~cm}$. Variasi pengurangan massa dilakukan dengan memvariasikan jari-jaridalam rim. Untuk tiap variasi, dilakukan perhitungan untuk mendapatkan jumlah massa yang dapat dikurangi dan momen inersia massa dari benda putar. Ternyata pada nilai jari-jari dalam tertentu, dapat diperoleh nilai kompromi dari permasalahan diatas.
\end{abstract}

Kata kunci: benda putar, penghematan bahan, momen inersia massa.

\begin{abstract}
Machine consists of a set of machine elements that still and moving. Machine elements that move in a circular motion called rotary object. In some cases it is often desirable reduction in the mass of the rotating object for economic reasons, usually for a mass production of machine elements. But the mass reduction results in a reduction in moment of inertia of the mass. If the demands of the design allow this decrease of moment of inertia, mass reduction is not a problem. But if the moment of inertia of the masses should not be too low, it must find a compromise in which a mass reduction profusely but the decrease in the mass moment of inertia of the smallest. In this research conducted a case study of rotating element radius of $10 \mathrm{~cm}$, radius of the hub $2 \mathrm{~cm}$ and outer radius hub $4 \mathrm{~cm}$. The number of spoke are 4 with a width of $1 \mathrm{~cm}$ and uniform thickness $0.5 \mathrm{~cm}$ all over rotating element. Variations mass reduction is done by varying the inner radius of the rim. For each variation, calculation is performed to obtain the amount of mass that can be reduced and the mass moment of inertia of the rotating object. It turned out that in the certain value of inner radius of the rim in particular, can compromise the values obtained from the above problem.
\end{abstract}

Keywords: rotating element, reducing material, mass moment of inertia. 


\section{PENDAHULUAN}

Secara umum gerak dapat dibagi menjadi tiga jenis gerakan. Pertama adalah gerak lurus yang dicirikan dengan lintasan berbentuk garis lurus. Kedua adalah gerakan berputar yang dicirikan dengan lintasan berupa lingkaran. Ketiga adalah gerakan gabungan antara gerak lurus dan gerak berputar. Ketiga jenis gerakan ini dapat terjadi pada komponen-komponen mesin. Pada gerak lurus, massa adalah besaran yang berpengaruh dan menentukan karakteristik gerak lurus itu sendiri. Sedangkan pada gerak berputar, besaran yang berpengaruh adalah momen inersia massa. Mesin terdiri dari sekumpulan elemen mesin yang diam dan bergerak. Elemen mesin yang bergerak dengan gerakan berputar disebut benda putar.

Pada beberapa kasus seringkali diinginkan pengurangan massa dari benda putar tersebut untuk alasan ekonomis. Dengan pengurangan massa, berarti pengurangan material yang berarti penghematan ongkos produksi. Hal tersebut biasanya terjadi untuk elemen mesin yag diproduksi massal. Namun pengurangan massa berakibat pada pengurangan momen inersia massa benda putar bersangkutan. Jika tuntutan perancangan tidak mempermasalahkan perubahan tersebut, maka pengurangan massa tidak menjadi masalah. Namun jika momen inersia massa tidak boleh terlalu rendah, maka harus dicari kompromi dimana pengurangan massa sebesar-besarnya namun penurunan momen inersia massa sekecil-kecilnya.

Persamaan-persamaan yang ditampilkan pada makalah ini dirumuskan sendiri oleh penulis dari persamaan-persamaan dasar dengan memperhatikan geometri benda putar. Persamaan-persamaan dasar yang dimaksud adalah persamaan volume dari bentuk dasar silinder berongga dan balok, persamaan kerapatan serta persamaan momen inersia massa untuk benda-benda sederhana. Karena itu meskipun cukup banyak persamaan ditampilkan, sebagian besar tidak ditampilkan rujukannya, kecuali untuk persamaan teorema sumbu sejajar. Jadi paper ini tidak berisi hal yang baru, tapi merupakan penerapan perhitungan pada kasus khusus benda putar berdiamer $10 \mathrm{~cm}$.

\section{METODOLOGI}

Penelitian ini menggunakan langkah-langkah seperti yang ditunjukkan pada diagram alir di Gambar 1 . Langkah pertama adalah mengasumsikan kerapatan bahan yang digunakan untuk benda putar. Disini dipilih $\rho=0,00783 \mathrm{~kg} / \mathrm{cm}^{3}$. Jumlah jari-jari z dipilih 4 (lihat Gambar 2) dengan lebar $1 \mathrm{~cm}$ dan tebal benda putar $0,5 \mathrm{~cm}$. Radius dalam hub dipilih $r_{\mathrm{H} 1}=2 \mathrm{~cm}$ dan radius luar hub $r_{\mathrm{H} 2}=4 \mathrm{~cm}$. Diameter terluar dipilih $r_{\mathrm{R} 2}=10 \mathrm{~cm}$.

Langkah kedua mengasumsikan radius-dalam rim $r_{\mathrm{R} 1}$. Besaran inilah yang divariasikan sehingga besar rongga / lubang bervariasi pula. Dengan bertambah besarnya nilai ini akan mengakibatkan perubahan jumlah materi bahan dan nilai momen inersia massa.

Supaya perhitungan dapat dipermudah, maka bentuk jari-jari disederhanakan dan dianggap sebagai balok persegi panjang berukuran panjang $(l)$ dikali lebar $(b)$ dan dikali tebal $(t)$. Pada langkah ketiga, lebar dan tebal diasumsikan $1 \mathrm{~cm}$ dan $0,5 \mathrm{~cm}$ sedangkan panjang ditentukan oleh persamaan:

$$
l=r_{R 1}-r_{H 2}
$$

Jarak pusat massa balok tersebut ke pusat putaran $O$ dapat dihitung dengan persamaan:

$$
d=0,5 l+r_{H 2}
$$




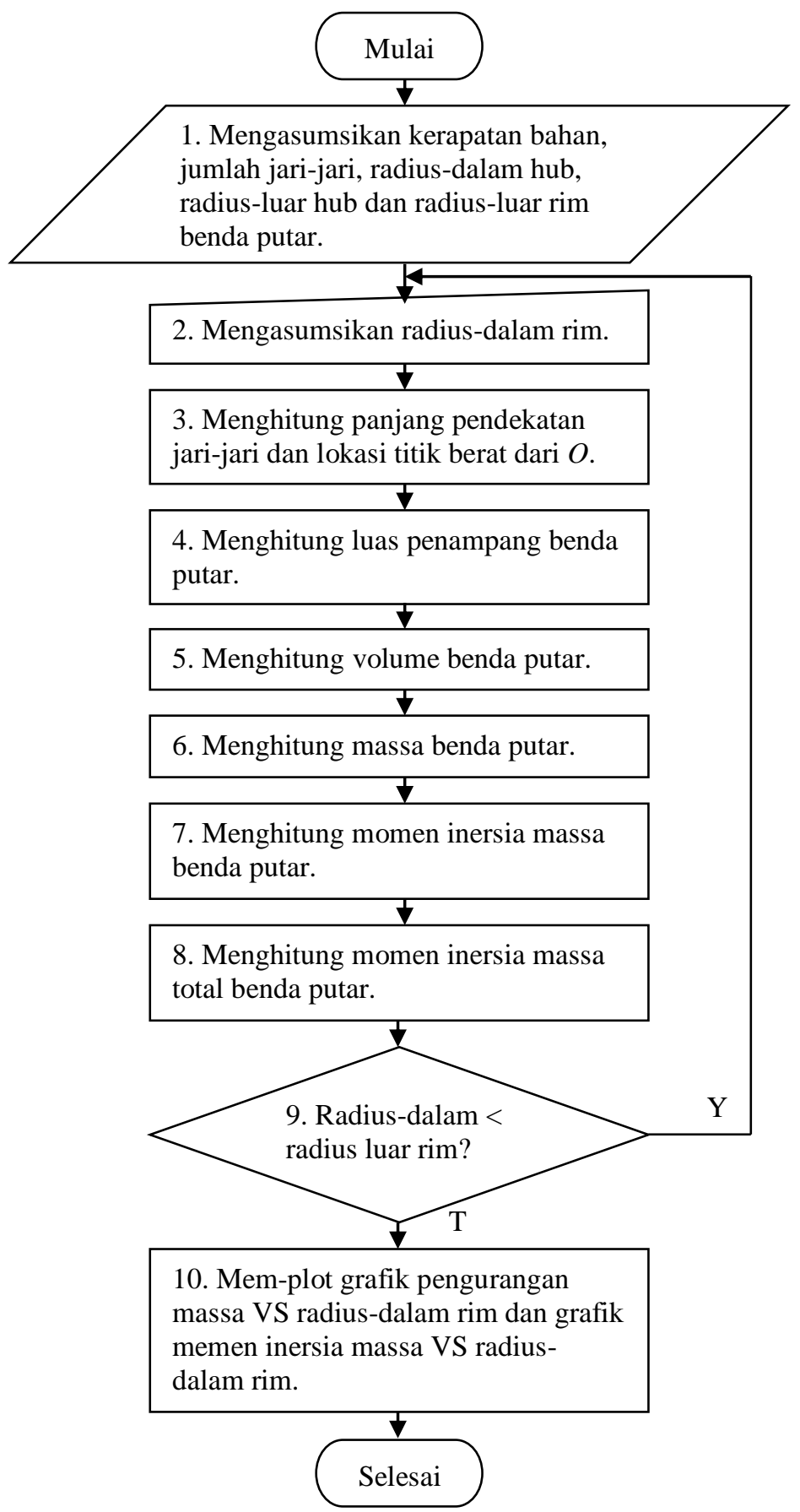

\section{Gambar 1. Diagram alir metodologi penelitian}

Langkah keempat adalah menghitung luas penampang benda putar. Pertama dihitung luas keseluruhan benda putar dikurangi luas lingkaran dalam hub tempat masuknya poros. Kemudian dihitung luas penampang hub, luas penampang jari-jari, dan luas penampang rim menggunakan persamaanpersamaan berikut: 


$$
\begin{aligned}
& A_{P S}=\pi \cdot\left(r_{R 2}{ }^{2}-r_{H 1}{ }^{2}\right) \\
& A_{P H}=\pi\left(r_{H 2}{ }^{2}-r_{H 1}{ }^{2}\right) \\
& A_{J}=b \cdot l \cdot z \\
& A_{P R}=\pi\left(r_{R 2}{ }^{2}-r_{R 1}{ }^{2}\right)
\end{aligned}
$$

Luas netto penampang dapat dihitung dengan menjumlahkan persamaan (4), (5) dan 6) seperti ditunjukkan persamaan (7) berikut:

$$
A_{N}=A_{P H}+A_{J}+A_{P R}=\pi\left(r_{H 2}{ }^{2}-r_{H 1}{ }^{2}\right)+b \cdot l \cdot z+\pi\left({r_{R 2}}^{2}-r_{R 1}{ }^{2}\right)
$$

Dan persamaan (8) untuk menghitung luas penampang rongga:

$$
A_{K}=A_{P S}-A_{N}=\pi \cdot r_{R 2}{ }^{2}-\left[\pi\left(r_{H 2}{ }^{2}-r_{H 1}{ }^{2}\right)+b \cdot l \cdot z+\pi\left(r_{R 2}{ }^{2}-r_{R 1}{ }^{2}\right)\right\rfloor
$$

Langkah kelima pada diagram alir menunjukkan perhitungan berikutnya adalah menghitung volume benda putar. Persamaan untuk memperoleh volume adalah:

$$
\begin{aligned}
& V_{S}=A_{P S} \cdot t=\pi \cdot\left(r_{R 2}{ }^{2}-r_{H 1}{ }^{2}\right) \cdot t \\
& V_{H}=A_{P H} \cdot t=\pi\left(r_{H 2}{ }^{2}-r_{H 1}{ }^{2}\right) \cdot t \\
& V_{J}=A_{J} \cdot t=b \cdot l \cdot z \cdot t \\
& V_{R}=A_{P R} \cdot t=\pi\left({r_{R 2}}^{2}-r_{R 1}{ }^{2}\right) \cdot t
\end{aligned}
$$

Dimana $V_{\mathrm{S}}$ adalah volume benda putar sebelum diberi rongga, $V_{\mathrm{H}}$ adalah volume hub, $V_{\mathrm{J}}=$ Volume jari-jari dan $V_{R}$ adalah volume Rim. Volume netto dapat diperoleh dari persamaan (13), sedangkan volume rongga ditunjukkan oleh $V_{\mathrm{K}}$ :

$$
\begin{aligned}
& V_{N}=V_{H}+V_{J}+V_{R}=\pi\left({r_{H 2}}^{2}-r_{H 1}{ }^{2}\right) \cdot t+b \cdot l \cdot z \cdot t+\pi\left(r_{R 2}{ }^{2}-r_{R 1}{ }^{2}\right) \cdot t \\
& V_{K}=V_{S}-V_{N}=\pi \cdot\left(r_{R 2}{ }^{2}-{r_{H 1}}^{2}\right) \cdot t-\left\lfloor\pi\left(r_{H 2}{ }^{2}-r_{H 1}{ }^{2}\right)+b \cdot l \cdot z+\pi\left(r_{R 2}{ }^{2}-r_{R 1}{ }^{2}\right)\right] \cdot t
\end{aligned}
$$

Langkah berikutnya menurut diagram alir adalah langkah keenam, yaitu menghitung massa benda putar. Menentukkan massa dapat dilakukan dengan mengalikan persamaan volume yang sudah diperoleh dari persamaan-persamaan sebelumnya dengan kerapatan yang sudah diasumsikan.

$m_{\mathrm{H}}$ adalah massa hub, $m_{\mathrm{J}}$ adalah massa jari-jari, $m_{\mathrm{R}}$ adalah massa rim dan $m_{\mathrm{K}}$ adalah massa yang dihilangkan dari benda putar sehingga diperoleh rongga.

$$
\begin{gathered}
m_{H}=\rho \cdot V_{H}=\rho \cdot \pi\left({r_{H 2}}^{2}-{r_{H 1}}^{2}\right) \cdot t \\
m_{J}=\rho \cdot V_{J}=\rho \cdot b \cdot l \cdot z \cdot t \\
m_{R}=\rho \cdot V_{R}=\rho \cdot \pi\left({r_{R 2}}^{2}-r_{R 1}{ }^{2}\right) \cdot t \\
m_{K}=\rho \cdot V_{K}=\rho \cdot\left\{\pi \cdot\left({r_{R 2}}^{2}-r_{H 1}{ }^{2}\right) \cdot t-\left\lfloor\pi\left({r_{H 2}}^{2}-{r_{H 1}}^{2}\right)+b \cdot l \cdot z+\pi\left({r_{R 2}}^{2}-r_{R 1}{ }^{2}\right)\right] \cdot t\right\}
\end{gathered}
$$

Langkah ketujuh adalah menghitung momen inersia massa dari benda putar. $J_{\mathrm{H}}$ adalah momen inersia massa hub, sedangkan $J_{\mathrm{R}}$ adalah momen inersia massa rim terhadap sumbu-nya. $J_{\mathrm{J}}$ adalah momen inersia massa jari-jari terhadap sumbu putar benda putar. $J_{\mathrm{j}}$ dapat dihitung dengan menghitung momen Inersia massa terhadap titik beratnya sendiri dan kemudian ditambah perkalian massa balok bersangkutan dengan kuadrat jarak titik berat ke sumbu yang melalui $O$, yaitu $d^{2}$, yang dikenal dengan teorema sumbu sejajar [1]. 


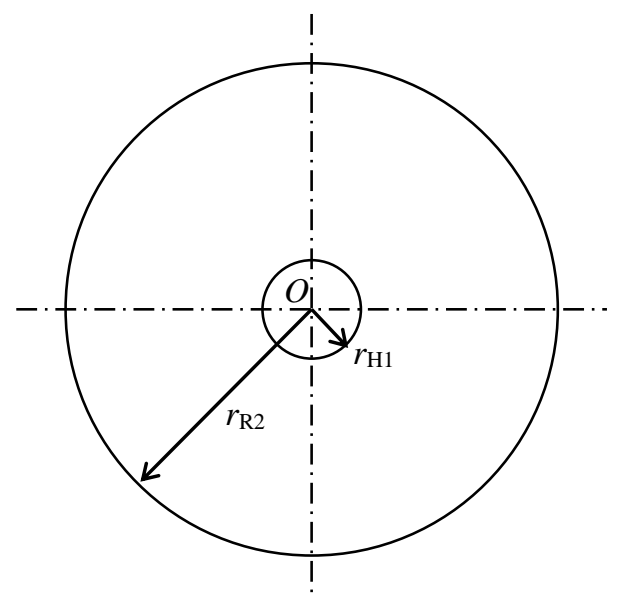

(a)

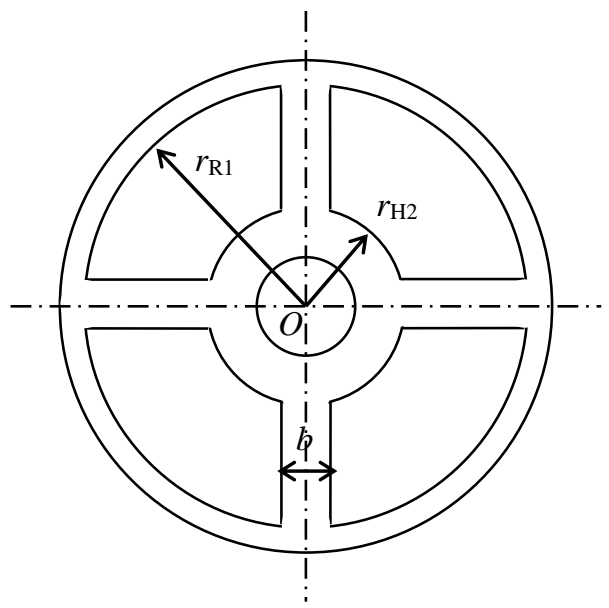

(b)

Gambar 2. a) Benda putar sebelum pengurangan massa. b) Benda putar setelah pengurangan massa

$$
\begin{aligned}
& J_{H}=0,5 \cdot m_{H} \cdot\left({r_{H 1}}^{2}+{r_{H 2}}^{2}\right)=0,5 \cdot \rho \cdot \pi\left({r_{H 2}}^{2}-r_{H 1}{ }^{2}\right) \cdot t \cdot\left({r_{H 1}}^{2}+{r_{H 2}}^{2}\right) \\
& J_{J}=12^{-1} \cdot m_{J} \cdot l^{2}+m_{J} \cdot d^{2}=12^{-1} \cdot \rho \cdot b \cdot l \cdot z \cdot t \cdot l^{2}+\rho \cdot b \cdot l \cdot z \cdot t \cdot d^{2} \\
& J_{R}=0,5 \cdot m_{R} \cdot\left({r_{R 1}}^{2}+r_{R 2}{ }^{2}\right)=0,5 \cdot \rho \cdot \pi\left({r_{R 2}}^{2}-r_{R 1}{ }^{2}\right) \cdot t \cdot\left({r_{R 1}}^{2}+r_{R 2}{ }^{2}\right)
\end{aligned}
$$

Akhirnya, pada langkah ke delapan, momen inersia massa total, $J_{\mathrm{T}}$, dapat dihitung dengan menjumlahkan semua momen inersia sebelumnya:

$$
\begin{aligned}
& J_{T}=J_{H}+J_{J}+J_{R}=0,5 \cdot \rho \cdot \pi\left({r_{H 2}}^{2}-{r_{H 1}}^{2}\right) \cdot t \cdot\left({r_{H 1}}^{2}+{r_{H 2}}^{2}\right)+12^{-1} \cdot \rho \cdot b \cdot l \cdot z \cdot t \cdot l^{2}+\rho \cdot b \cdot l \cdot z \cdot t \cdot d^{2} \\
& +0,5 \cdot \rho \cdot \pi\left({r_{R 2}}^{2}-{r_{R 1}}^{2}\right) \cdot t \cdot\left({r_{R 1}}^{2}+{r_{R 2}}^{2}\right)
\end{aligned}
$$

Setelah selesai menghitung momen inersia penampang untuk $r_{\mathrm{R} 1}=4,5 \mathrm{~cm}$, selama $r_{\mathrm{R} 1}<r_{\mathrm{R} 2}$, perhitungan kembali dilakukan dengan nilai radius dalam rim diperbesar $0,5 \mathrm{~cm}$. Jadi, langkah ke sembilan ini adalah looping. Semua hasil perhitungan kemudian dicantumkan pada Tabel 1.

Langkah terakhir adalah mem-plot grafik pengurangan massa benda berputar VS radius-dalam rim dan momen inersia massa benda berputar VS radius-dalam rim. 


\section{HASIL DAN PEMBAHASAN}

Tabel 1. Hasil Perhitungan

\begin{tabular}{|c|c|c|c|c|c|c|c|c|c|c|c|}
\hline \multirow{2}{*}{ No } & $r_{\mathrm{R} 1}$ & $l$ & $d$ & $A_{\mathrm{PS}}$ & $A_{\mathrm{PH}}$ & $A_{\mathrm{J}}$ & $A_{\mathrm{PR}}$ & \multicolumn{2}{|c|}{$A_{\mathrm{N}}$} & \multicolumn{2}{|c|}{$A_{\mathrm{K}}$} \\
\cline { 2 - 12 } & $\mathrm{cm}$ & $\mathrm{cm}$ & $\mathrm{cm}$ & $\mathrm{cm}^{2}$ & $\mathrm{~cm}^{2}$ & $\mathrm{~cm}^{2}$ & $\mathrm{~cm}^{2}$ & $\mathrm{~cm}^{2}$ & $\%$ & $\mathrm{~cm}^{2}$ & $\%$ \\
\cline { 2 - 12 } & 1 & 2 & 3 & 4 & 5 & 6 & 7 & 8 & 9 & 10 & 11 \\
\hline \hline 1 & 4,5 & 0,5 & 4,25 & 301,59 & 37,70 & 2,00 & 250,54 & 290,24 & 96,24 & 11,35 & 3,76 \\
\hline 2 & 5,0 & 1,0 & 4,50 & 301,59 & 37,70 & 4,00 & 235,62 & 277,32 & 91,95 & 24,27 & 8,05 \\
\hline 3 & 5,5 & 1,5 & 4,75 & 301,59 & 37,70 & 6,00 & 219,13 & 262,83 & 87,15 & 38,77 & 12,85 \\
\hline 4 & 6,0 & 2,0 & 5,00 & 301,59 & 37,70 & 8,00 & 201,06 & 246,76 & 81,82 & 54,83 & 18,18 \\
\hline 5 & 6,5 & 2,5 & 5,25 & 301,59 & 37,70 & 10,00 & 181,43 & 229,13 & 75,97 & 72,47 & 24,03 \\
\hline 6 & 7,0 & 3,0 & 5,50 & 301,59 & 37,70 & 12,00 & 160,22 & 209,92 & 69,60 & 91,67 & 30,40 \\
\hline 7 & 7,5 & 3,5 & 5,75 & 301,59 & 37,70 & 14,00 & 137,44 & 189,14 & 62,71 & 112,45 & 37,29 \\
\hline 8 & 8,0 & 4,0 & 6,00 & 301,59 & 37,70 & 16,00 & 113,10 & 166,80 & 55,31 & 134,80 & 44,69 \\
\hline 9 & 8,5 & 4,5 & 6,25 & 301,59 & 37,70 & 18,00 & 87,18 & 142,88 & 47,37 & 158,71 & 52,63 \\
\hline 10 & 9,0 & 5,0 & 6,50 & 301,59 & 37,70 & 20,00 & 59,69 & 117,39 & 38,92 & 184,20 & 61,08 \\
\hline
\end{tabular}

\begin{tabular}{|c|c|c|c|c|c|c|c|c|}
\hline \multirow{2}{*}{ No } & $V_{\mathrm{S}}$ & $V_{\mathrm{H}}$ & $V_{\mathrm{J}}$ & $V_{\mathrm{R}}$ & \multicolumn{2}{|c|}{$V_{\mathrm{N}}$} & \multicolumn{2}{|c|}{$V_{\mathrm{K}}$} \\
\cline { 2 - 9 } & $\mathrm{cm}^{3}$ & $\mathrm{~cm}^{3}$ & $\mathrm{~cm}^{3}$ & $\mathrm{~cm}^{3}$ & $\mathrm{~cm}^{3}$ & $\%$ & $\mathrm{~cm}^{3}$ & $\%$ \\
\cline { 2 - 9 } & 12 & 13 & 14 & 15 & 16 & 17 & 18 & 19 \\
\hline \hline 1 & 150,80 & 18,85 & 1,00 & 125,27 & 145,12 & 96,24 & 5,68 & 3,76 \\
\hline 2 & 150,80 & 18,85 & 2,00 & 117,81 & 138,66 & 91,95 & 12,14 & 8,05 \\
\hline 3 & 150,80 & 18,85 & 3,00 & 109,56 & 131,41 & 87,15 & 19,38 & 12,85 \\
\hline 4 & 150,80 & 18,85 & 4,00 & 100,53 & 123,38 & 81,82 & 27,42 & 18,18 \\
\hline 5 & 150,80 & 18,85 & 5,00 & 90,71 & 114,56 & 75,97 & 36,23 & 24,03 \\
\hline 6 & 150,80 & 18,85 & 6,00 & 80,11 & 104,96 & 69,60 & 45,84 & 30,40 \\
\hline 7 & 150,80 & 18,85 & 7,00 & 68,72 & 94,57 & 62,71 & 56,22 & 37,29 \\
\hline 8 & 150,80 & 18,85 & 8,00 & 56,55 & 83,40 & 55,31 & 67,40 & 44,69 \\
\hline 9 & 150,80 & 18,85 & 9,00 & 43,59 & 71,44 & 47,37 & 79,36 & 52,63 \\
\hline 10 & 150,80 & 18,85 & 10,00 & 29,85 & 58,69 & 38,92 & 92,10 & 61,08 \\
\hline
\end{tabular}

\begin{tabular}{|c|c|c|c|c|c|c|c|c|c|}
\hline \multirow{3}{*}{ No } & $m_{\mathrm{H}}$ & $m_{\mathrm{J}}$ & $m_{\mathrm{R}}$ & $m_{\mathrm{T}}$ & $m_{\mathrm{K}}$ & $J_{\mathrm{H}}$ & $J_{\mathrm{J}}$ & $J_{\mathrm{R}}$ & $J_{\mathrm{T}}$ \\
\cline { 2 - 10 } & $\mathrm{kg}$ & $\mathrm{kg}$ & $\mathrm{kg}$ & $\mathrm{kg}$ & $\mathrm{kg}$ & $\mathrm{kg} . \mathrm{cm}^{2}$ & $\mathrm{~kg} \cdot \mathrm{cm}^{2}$ & $\mathrm{~kg} \cdot \mathrm{cm}^{2}$ & $\mathrm{~kg} \cdot \mathrm{cm}^{2}$ \\
\cline { 2 - 10 } & 20 & 21 & 22 & 23 & 24 & 25 & 26 & 27 & 28 \\
\hline \hline 1 & 0,148 & 0,008 & 0,981 & 1,136 & 0,044 & 1,476 & 0,142 & 76,692 & 78,309 \\
\hline 2 & 0,148 & 0,016 & 0,922 & 1,086 & 0,095 & 1,476 & 0,318 & 76,333 & 78,127 \\
\hline 3 & 0,148 & 0,023 & 0,858 & 1,029 & 0,152 & 1,476 & 0,534 & 75,225 & 77,236 \\
\hline 4 & 0,148 & 0,031 & 0,787 & 0,966 & 0,215 & 1,476 & 0,793 & 73,206 & 75,475 \\
\hline 5 & 0,148 & 0,039 & 0,710 & 0,897 & 0,284 & 1,476 & 1,099 & 70,096 & 72,672 \\
\hline 6 & 0,148 & 0,047 & 0,627 & 0,822 & 0,359 & 1,476 & 1,456 & 65,706 & 68,638 \\
\hline 7 & 0,148 & 0,055 & 0,538 & 0,740 & 0,440 & 1,476 & 1,868 & 59,830 & 63,174 \\
\hline 8 & 0,148 & 0,063 & 0,443 & 0,653 & 0,528 & 1,476 & 2,339 & 52,248 & 56,062 \\
\hline 9 & 0,148 & 0,070 & 0,341 & 0,559 & 0,621 & 1,476 & 2,872 & 42,727 & 47,075 \\
\hline 10 & 0,148 & 0,078 & 0,234 & 0,460 & 0,721 & 1,476 & 3,471 & 31,022 & 35,969 \\
\hline
\end{tabular}




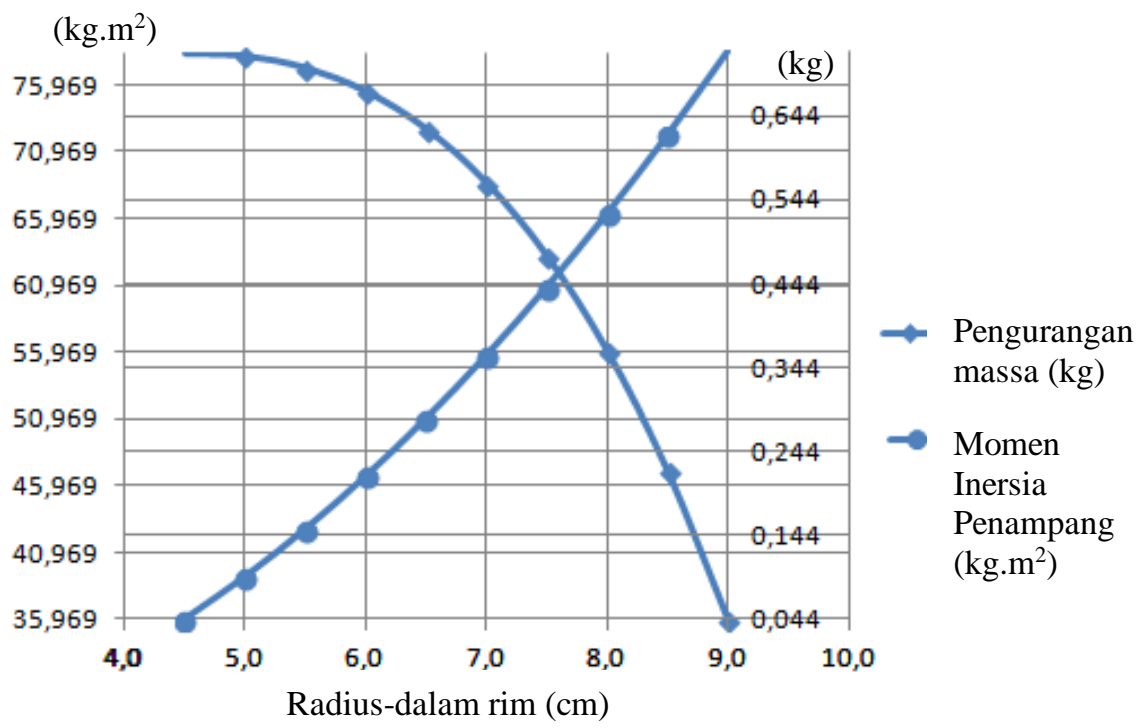

\section{Gambar 3. Grafik pengaruh ukuran radius dalam rim terhadap nilai momen inersia massa dan pengurangan material (massa)}

Setelah diplot, terlihat, ternyata bertambahnya ukuran radius-dalam rim mengakibatkan bertambahnya pengurangan material benda berputar, karena akan terbentuk rongga yang lebih besar yang berarti pemakaian bahan menjadi lebih sedikit. Pengurangan ini berbanding lurus tapi tidak linier.

Demikian juga dengan nilai momen inersia penampang, terjadi perubahan nilai besaran tersebut dengan bertambahnya ukuran radius dalam rim. Bedanya nilai momen inersia menjadi lebih kecil.

\section{SIMPULAN}

Dari tabel dan grafik terbukti bahwa bertambah besarnya radius dalam rim akan memperbesar rongga yang berarti berkurangnnya material sehingga jika benda putar adalah produk massal, maka perbesaran rongga adalah cara untuk menurunkan biaya produksi per produk. Tetapi ternyata dengan berkurangnya material, nilai momen inersia massa jadi berkurang. Jika rancangan mensyaratkan nilai momen inersia harus cukup besar, maka harus dapat dibuat kompromi antara keinginan menghemat material dan mempertahankan nilai momen inersia massa.

\section{DAFTAR PUSTAKA}

[1] Sears, Zemansky, Young, Freedman, (2010). Fisika Universitas, Ed. 10, Erlangga, Jakarta

[2] Popov, E.P., (1984). Mekanika Teknik, Erlangga, Jakarta.

[3] Beer, Ferdinand P., (2009). Vector Mechanics for Engineers - Statics and Dynamics, McGraw Hill, New York. 